\title{
Home Experiments in Mechanical Engineering
}

\author{
Latif M. Jiji, Feridun Delale and Benjamin Liaw \\ The City College of The City University of New York
}

\begin{abstract}
This paper describes 14 experiments in mechanical Engineering which students can perform at home using readily available supplies. The experiments are designed for integration with lecture courses in thermodynamics, fluid flow, heat transfer and solid mechanics. hey represent applications of theoretical concepts taught in mechanical engineering, In each experiment theoretical predictions are compared with experimentally obtained results. Although crude measuring techniques are used at home, comparison between theoretical and experimental results is usually satisfactory.

A key feature of the experiments is that they are simple and easy to carry out, requiring approximately one hour to perform. Aside from enhancing students' comprehension of theoretical concepts, they provide opportunities for hands-on experience-, encourage resourcefulness and raise questions about accuracy, approximations, assumptions and modeling. Experience with home experiment assignments at the City College has demonstrated their utility as an effective learning tool. In general students enjoy doing the experiments and view them as a welcomed departure from traditional assignments.
\end{abstract}

\section{Introduction and Previous Studies}

The idea of performing hands-on experiments using simple, inexpensive and readily available supplies has long been adopted extensively in high school and college science courses [1-5]. The practice usually involves a careful coordination of experiments with theoretical principles central in the course. Its main goal is to address the important question: "How to simplify, approximate and model a complicated, physical phenomenon into a theory and what is the error induced during the process of idealization?" Recently, this pedagogy has also been introduced into engineering courses. Regan et al. [6] described four laboratory experiments using edible materials. In an attempt to construct an efficient curriculum, Giorgetti [7] combined theory and laboratory experiment into a single course on fluid mechanics. Dvorak [8] discussed integration of a simple experiment in heat transfer with analytical solution and computer simulation. More recentl y, authors of this paper presented a new teaching methodology using home experiments [9]. Our approach integrates simple home experiments with lecture courses to develop interest, understanding and appreciation for theory. In this paper fourteen home experiments that can be readily adopted into courses of thermodynamics, fluid flow, heat transfer and solid mechanics are presented. Feedback from student evaluation is also shown. The purpose of this project is to use home experiments to improve students' comprehension in theoretical and laboratory courses. It is expected that significant learning will take place when students perform experiments at home. Carrying out the home-experiment assignments is expected to help students translate what seem to be abstract theoretical concepts into physical realities.

\section{IL Concept Description}

The simple experiment concept is distinguished by several important features. First, it addresses a broad segment of the undergraduate engineering curriculum affecting lecture courses in several disciplines. Second, it can be easily integrated with existing lecture courses and does not require curriculum changes. Third, it makes minimal demands on the instructor's time. Fourth, it increases students' involvement and thereby increases their motivation to learn. Fifth, it trains students in the processes of Simplification approximation and modeling. Sixth, it creates an environment which inspires innovation and improvisation. In our opinions, each experiment should be carefully selected to meet the following critical requirements: 
(1) It must deal with a topic which is considered in the course and for which background information and theoretical solutions are normally given in class.

(2) It should, on first impression, strike students as being obviously simple and easy to perform, involving familiar situations and requiring readily available household materials and tools.

(3) Setting up the experiment and obtaining the necessary data should take less than an hour and a half.

(4) It should raise questions in the students' mind regarding both the experimental procedure and theoretical solution.

(5) Incorporating the experiment with homework assignments must not disrupt the normal progress of the course or take up additional class time.

\section{Description of Home Experiments}

\section{A. Thermodynamics}

$\mathrm{Al}$ Latent heat of ice: Prepare ice at $0^{\circ} \mathrm{C}$ and mixed it with water at boiling temperature until nearly all ice melts. Use the first law of thermodynamics to determine the latent heat of ice. Compare with published data.
Results: Home experiment latent heat $=338 \mathrm{~kJ} / \mathrm{kg}$
Error $=1.5 \%$

Published value: latent heat $=333 \mathrm{~kJ} / \mathrm{kg}$

A2 First law of thermodynamics: Prepare ice at $0^{\circ} \mathrm{C}$ using ice-water mixture. Heat several spoons in boiling water to 100 "C. Remove the spoons from the boilf water and mix them with a known amount of water at $\mathrm{O}^{\circ} \mathrm{C}$. Use a small electric heater (the kind used to heat water in a cup for tea or coffee) to heat the water-spoons mixture to $37^{\circ} \mathrm{C}$ (body temperate). Consider the water as a system. Heat $\mathrm{Q}$ is added to the water nom the spoons and work W (electric energy) is also added to the water. change in internal energy of the water is AU. Use data from this experiment to verif the first law of thermodynamics.
Results: Home experiment
$\Delta \mathrm{U} /(\mathrm{Q}-\mathrm{W})=1.15$
Error $=15 \%$
Published value:
$\Delta \mathrm{U} /(\mathrm{Q}-\mathrm{W})=1$

A3 Ideal gas law: Place an empty mug in boiling water at 100 "C. Attach the open end of a small plastic bag at the mouth of the mug and seal it with a rubber band around the rim. Cut a small hole at the bottom of the bag and allow the hot air to escape. Seal the hole. Prepare water at $\mathrm{O}^{\circ} \mathrm{C}$ by mixing it with ice. Remove the mug and place it in the ice-water mixture. Observe the bag being sucked into the mug as the air temperate drops from $100 " \mathrm{C}$ to $\mathrm{O}^{\circ} \mathrm{C}$. Measure the initial and final volumes of the air, VI and $\mathrm{V}_{2}$, calculate their ratio and compare with ideal gas prediction.

\section{Results: Home experiment: $V_{1} / V_{2}=1.42$}

Ideal gas law: $\quad V_{1} / V_{2}=T_{1} / T_{2}=1.37$

$$
\text { Error }=3.6 \%
$$
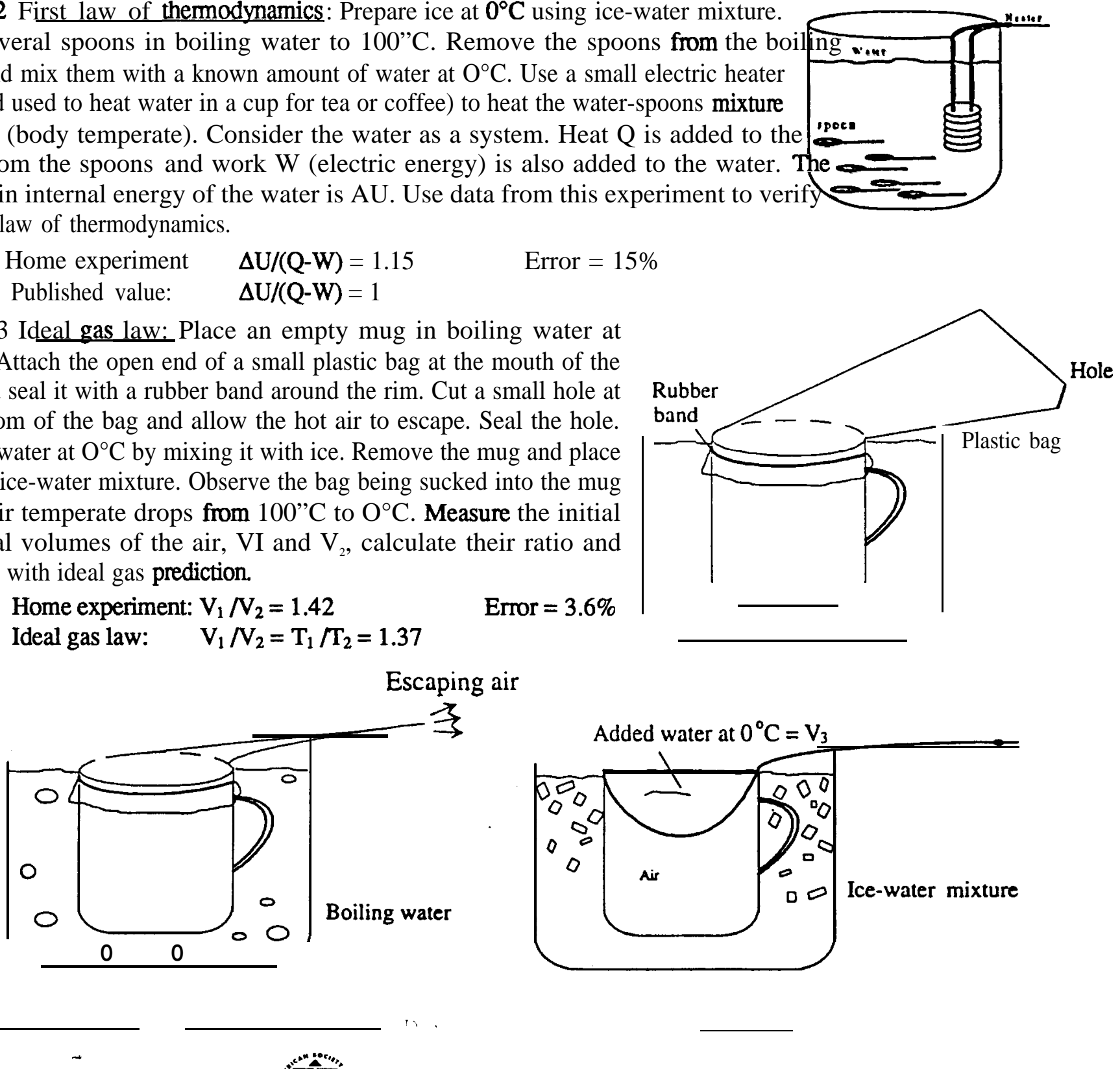


\section{B. Fluid Mechanics}

B1 Discharge velocity: Cut the top of an empty milk carton and punch a circular hole near its bottom. Place in the sink and fill with water. Adjust the flow rate to maintain a gentle overflow. Using flow rate measurement calculate the discharge velocity, $V_{o}$, and compare with results from Bernoulli's equation.

Results: Home experiment: $\quad V_{0}=137 \mathrm{~cm} / \mathrm{s}$

Bernoulli's equation: $\quad V_{0}=108 \mathrm{~cm} / \mathrm{s}$

Error $=26.8 \%$

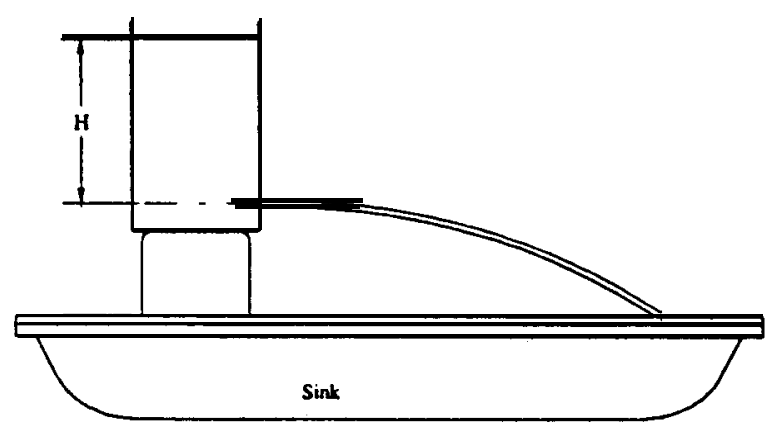

B2 Falling balloon: Inflate a balloon to a diameter of at least $30 \mathrm{~cm}$. Drop it from the ceiling and measure the time needed for the balloon to reach the floor. Compare the result with theoretical prediction of the drop time using Newton's law of motion taking into consideration drag and gravity forces.
Results:
$\begin{array}{ll}\text { Home experiment: } & \text { drop time }=3 \mathrm{~s} \\ \text { Newton's law: } & \text { drop time }=2.86 \mathrm{~s}\end{array}$
Error $=4.9 \%$

B3 Laminar flow through a tube: Attach several small diameter straws (coffee stirs) coaxially (end-tin end) to form a tube $65 \mathrm{~cm}$ long. Cut the top of an empty milk carton and punch a small hole $6 \mathrm{~cm}$ below the top. Insert one end of the tube through the hole and seal the carton around the straw to prevent leakage. Place the carton in the sink and support the tube horizontally making sure that both ends are at the same level. Fill the carton with cold water and allow it to gently overflow. Measure the flow rate and compare the result with theoretical prediction based on fully developed laminar flow theory.

Results: Home experiment flow rate $=0.98 \mathrm{~g} / \mathrm{s}$

Theory: flow rate $=1.04 \mathrm{~g} / \mathrm{s}$

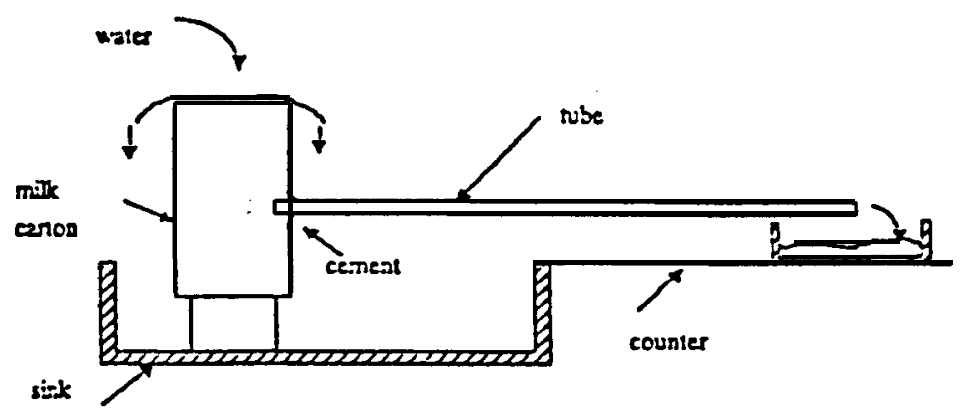

Error $=5.8 \%$

B4 Open channel flow: Construct a channel into the shape as shown by cutting quart-size milk carton and tape the channel to one of its top sides. Place the assembly in the sink with the channel inclined at approximately $10^{\circ}$ from the horizontal. Measure the angle of inclination. Turn the faucet on and fill the carton. Adjust the flow rate to maintain steady and smooth flow thorough the channel. Measure the flow rate and water film thickness. Compare with theoretical prediction of film thickness.

Results:

Home experiment:

Theory:

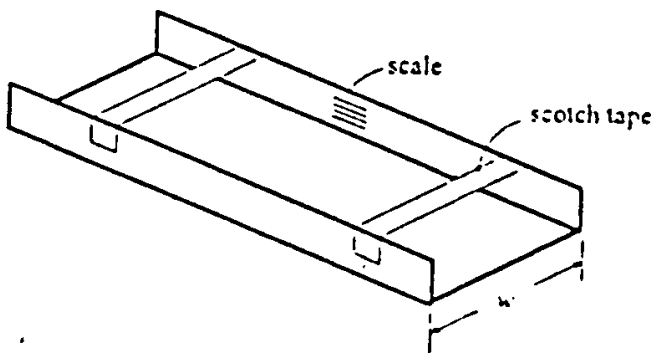

Error $=9.1 \%$

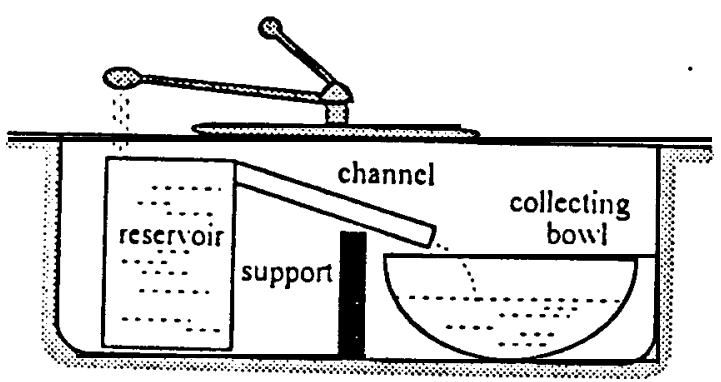


C. Heat Transfer

C1 Constant area fin: Fill a pot to the rim with water and bring it to boil. Cut a $35 \mathrm{~cm}$ long section from a metal wirohanger. Bend a $5 \mathrm{~cm}$ section at one end and immerse it in the boiling water. Support the wire in the horizontal position as shown. Use aluminum foil to shield the wire from the heating element or the flame of the stove. Determine the distance from the boiling water along the wire where the temperature drops to $37^{\circ} \mathrm{C}$ (body temperature). Compare the result with theoretical prediction using fin solution.

Results: Home experiment: distance from base $=4.5 \mathrm{~cm}$

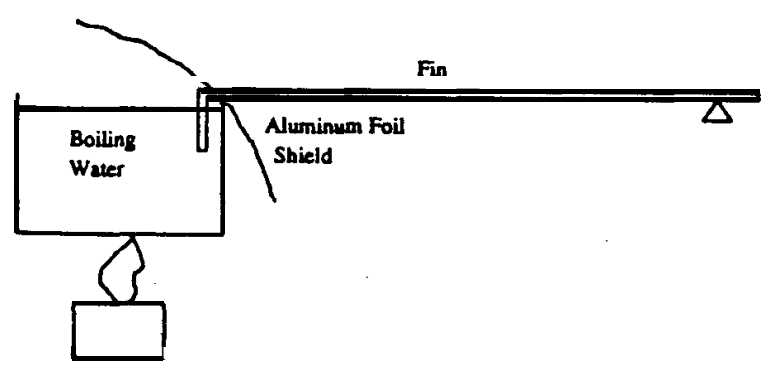

Fin theory: distance from base $=7.3 \mathrm{~cm}$

Error $=38.4 \%$

C2 Transient conduction: Place a $35 \mathrm{~cm}$ long section of a steel wire hanger in an oven and heat it to $150^{\circ} \mathrm{C}$. Remove the wire from the oven and suspend it horizontally in still air using simple supports as shown. Allow the wire to cool by natural convection. Measure the time needed for the surface temperate to drop to $37^{\circ} \mathrm{C}$ (body temperature). Compare the result with theoretical prediction with lumped capacitance analysis.

Results: Home experiment: $\quad$ cooling time $=\mathbf{1 1 8} \mathrm{s} \quad$ Error $=33 \%$

Lumped capacitance: cooling time $=176 \mathrm{~s}$

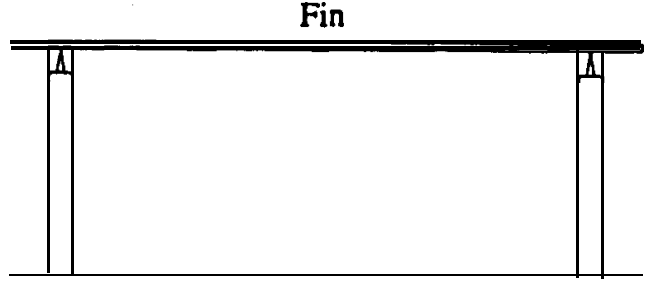

C3 Forced convection heat transfer coefficient for cylinder in cross flow: Undo a wire hanger to form a straight wire. Bend a $14 \mathrm{~cm}$ section of the wire at each end to $90^{\circ}$ as shown. The three sections should be in the same plane. Place the wire in an oven with one end extending outside. Close the oven door as best as you can and heat to $200^{\circ} \mathrm{C}$. Remove the wire from the oven, hold it by the cold $14 \mathrm{~cm}$ section and quickl y set it in a circular motion. Count the number of rotations and clocks the time elapsed. Stop the motion and touch the end section to see if it has cooled to $37^{\circ} \mathrm{C}$ (body temperature). Calculate heat transfer coefficient and compare with theoretical prediction using a correlation equation for a cylinder in forced convection cress flow.

$\begin{array}{llll}\text { Results: } & \text { Home experiment } & \mathrm{h}=133 \mathrm{~W} / \mathrm{m}^{2}-{ }^{\circ} \mathrm{C} & \text { Error }=22 \%\end{array}$

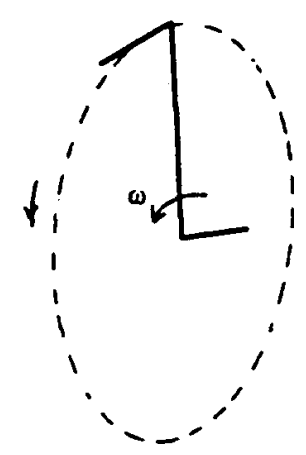

\section{Solid Mechanics}

D1 Elongation in axial loading: Suspend a ruler with two nylon fishing lines. Apply a load to the ruler at a point between the two lines and measure the elongations of the two lines. Compare the result with theoretical prediction.
Results:
Home experiment:
deflection at Pt $\mathrm{D}=16.5 \mathrm{~mm}$
Theory:
deflection at Pt $D=16.3 \mathrm{~mm}$
Error $=1.2 \%$

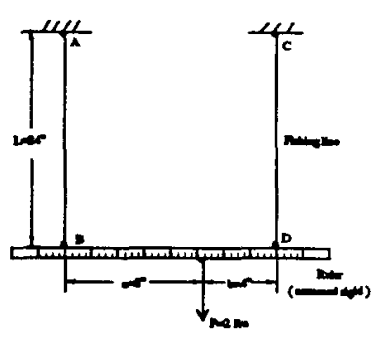

D2 Bending failure of a cbalk: Support a stick of chalk horizontally at both ends on two round pencils. Load the chalk by suspending a weight at its mid-span. Increase the load until failure occurs. Use theory and data from this test to predict failure due to a load at another location. Compare with experimental result.

Results: Home experiment: failure load $=1.9 \mathrm{~kg}$ Error $=2.7 \%$

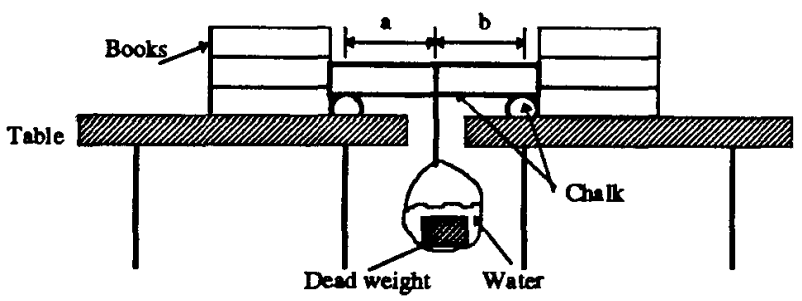

Theory:

failure load $=1.85 \mathrm{~kg}$

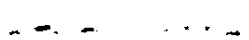


D3 Torsion failure of a chalk: Apply torsion to a stick of chalk by placing it vertically on a table and suspending a load with a string wrapped around the chalk. Increse the load until failure occurs. Compare the result with theoretical prediction.

Results: Home experiment: failure load $=6.2 \mathrm{~kg} \quad$ Error $=8.4 \%$

Theory: $\quad$ failure load $=6.77 \mathrm{~kg}$

D4 Deflection of a cantilever beam: Use a steel ruler as a beam. Cantilever the ruler over a table pressing firmly with one hand on one end. Apply a load at the free end and measure the corresponding deflection. Compare the result with theoretical prediction.

Results: Home experiment: deflection at Pt A $=5.69^{\prime \prime} \quad$ Error $=11 \%$ Theory:

deflection at $\mathrm{Pt} A=5.12$ "
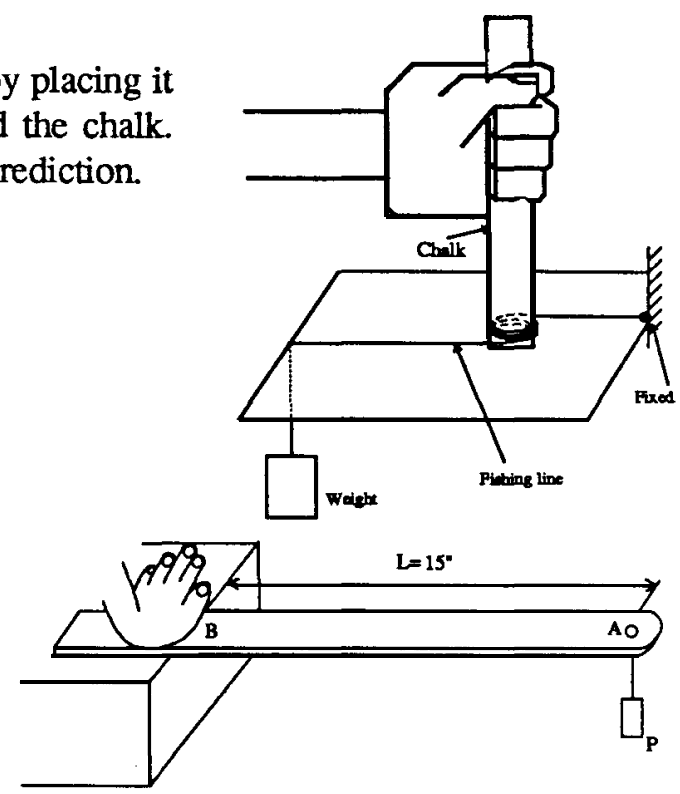

\section{Evaluation}

Course rating form were filled out by students in four courses: Thermodynamics, Fluid Mechanics, Heat Transfer, and Mechanics of Materials in the Department of Mechanical Engineering, City College of New York, in both the fall and spring semesters, 1994-95, allowing them to judge the quality of the home experiment along several dimensions. Results of these surveys are summarized in the figure below. The questions included in the survey were:

- Whether the experiment was easy or hard to do (UNDERSTAND, 1 = easy);

- Whether the experiment was easy or difficult to perform (PERFORM, $1=$ easy);

- Whether the experiment helped understand theory (THEORY, 1 = yes, a lot);

- Whether distraction was a problem at home (DISTRACT, 1 = yes, very much):

- Whether the experiment was enjoyable (ENJOY, 1 = yes, a lot);

- Whether the experiment took longer than they expected (TIME, 1 = a lot less time);

- Whether the experiment encouraged wanting to leam more about the theory (LEARNING, $1=$ not at all).

HOME EXPERIMENT RATINGS BY COURSE

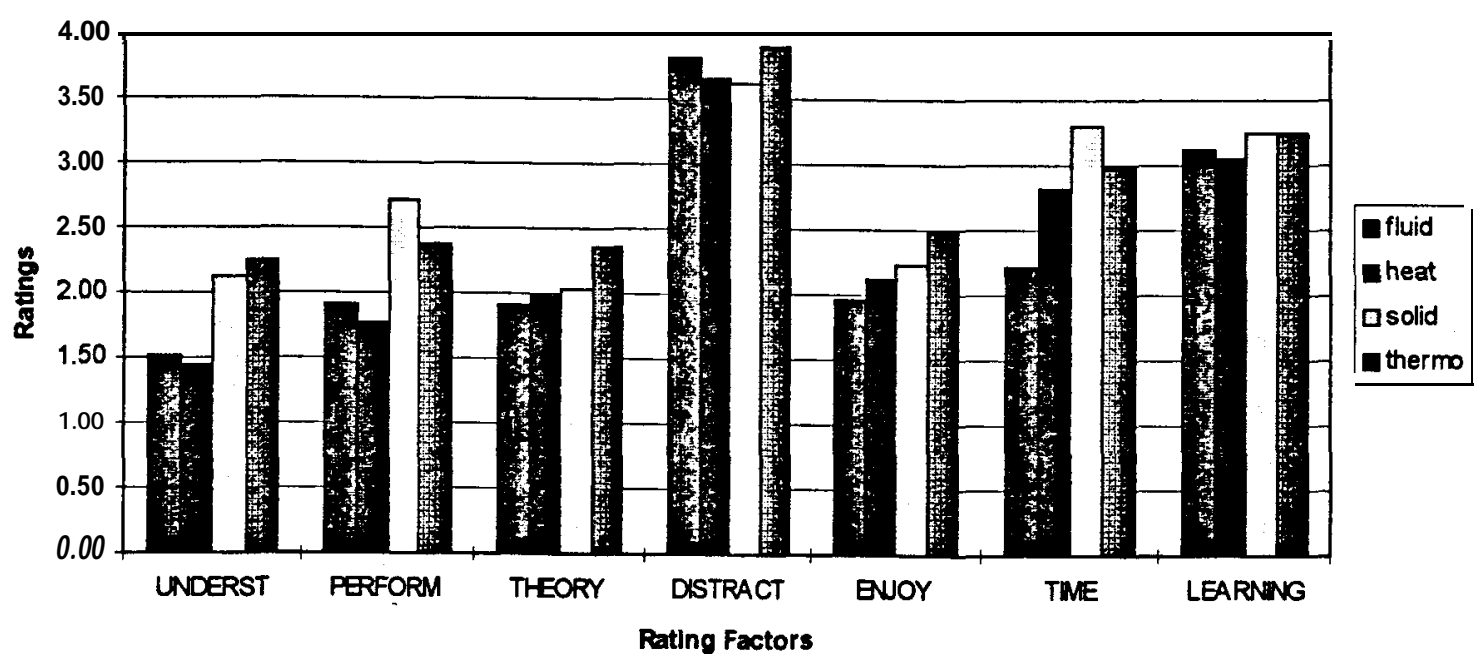

Means, standard deviations and a bar graph repenting mean difference for each rating in each of four courses are shown in the figure. A MANOVA revealed significant effects for three of the ratings: easy to understand ...................... 
(UNDERSTAND), helped understand theory (THEORY), how long it took (TIME). Students in the "SOLID' and "THERAO". courses found the home-experiment instructions more difficult to understand and more difficult to perform than did students in the "FLUID' and "HEAT' courses. The 'SOLID' students found that the experiments took significantly more time than they expected when compared to all other students and the 'FLUID' students found they took less time than all other students. There were no differences between course ratings along the remaining dimensions. Most students found home experiments to be somewhat enjoyable; to encourage them to seek out more information about the underlying theory; and they were able to implement them without significant distraction. These findings help establish the usefulness of this teaching method and the need to understand its differential use in different content areas of the engineering curriculum.

\section{References}

1. Walker, J., The Flying Circus of Physics With Answers, Wiley, New York, 1977.

2. Edge, R. D., String \& Sticky Tapes Experiments, American Association of Physics Teachers, College Park, Maryland, 1980.

3. Bohren, C.F., Clouds in a Glass of Beer: Simple Experiments in Atmospheric Physics, Wiley, New York, 1987.

4. Bohren, C.F., What Light Through Yonder Window Breaks?: More Experiments in Atmospheric Physics, Wiley, New York, 1991.

5. Elrlich, R., Turning the World Inside Out, Princeton, New Jersey: Princeton University Press, 1990.

6. Regan, T. M., E.C. Menegaux and P.A. Minderman, Jr., Eatable Thermodynamic and Transport Phenomena for Simple Laboratory and Design Exercises, 1992 ASEE Annual Conference Proceedings, pp. 1661-1666.

7. Giorgetti, M.F., A New Approach for the Integration of Lectures and Laboratory in a Fluid Mechanics Course, 1992 ASEE Annual Conference Proceedings, pp. 1215-1218.

8. Dvorak, S.D., Introducing Simulation Concepts in a Simple Heat Transfer Experiment, 1992 ASEE Annual Conference Proceedings, pp. 1291-1294.

9. Jiji, L.M., F. Delale, B. Liaw, and Y. Wu, Home Experiments: Effective Tools in Engineering Education, 1995 ASEE Annual Conference Proceedings, pp. 2155-2159.

\section{Acknowledgment}

This project was supported by NSF grant No. DUE-9354365. Student evaluation was conducted by Dr. Debra Coates, Department of Psychology, City College of New York.

\section{LATIF M. JIJI}

Dr. Latif M. Jiji is the Herbert Kayser Professor of Mechanical Engineering at The City College of CUNY. He is a graduate of MIT (S.B.), Carnegie Institute of Technology (MS.) and the University of Michigan (Ph.D.). He taught at the University of Toledo and New York University before joining The City College. His research in the area of heat transfer has been supported by grants from NSF, NIH, NASA, ARO, OWRR, IBM, DEC, and AT\&T. His recent interests include studies in learning enhancement.

\section{FERIDUN DELALE}

Dr. Feridun Delale received his B.S. and M.S. degrees in Civil Engineering from the Technical University of Istanbul. After receiving his doctorate from Lehigh University in Applied Mechanics he taught at the Technical University of Istanbul, Lehigh and Drexel Universities. In 1984 he joined The City College of CUNY where he is currently Professor of Mechanical Engineering. Dr. Delale's research interests have included fracture mechanics, adhesively bonded joints, nonhomogeneous media and mechanics and damage of composite materials. He has also recently participated in ECSEL and contributed to the development of home experiments for Mechanics of Materials.

\section{BENJAMIN LIAW}

Professor Benjamin Liaw received his Ph.D. degree frm the University of Washington. He joined the faculty of the City College of CUNY in 1984, where he is currently Professor of Mechanical Engineering. He also serves as the School PI of ECSEL at CCNY and the ECSEL Coalition Co-PI for Manufacturing Education. The main charge of the coalition is to improve undergraduate engineering education through design for manufacturing across the curriculum. 